\title{
Brinquedo, memória de uma sociedade
}

Josseline Ivette Cabanne

Graduada em História, Cultura e Patrimônio. Professora pós-graduada em Educação Artística. Integrante da equipe docente do "Postgrado: La expresión en Educación Inicial" no Instituto Uruguaio de Educação pela Arte. Autora de obras e artigos em publicações vinculadas à Educação Artística e Patrimônio. Integrante da equipe diretora do Centro Uruguaio para o Desenvolvimento do Ser Humano (CEDESERH).

E-mail: jobearn@yahoo.com

O homem só é verdadeiramente homem quando brinca. Friedrich von Schiller

Resumo: O brinquedo, carregado de conotação simbólica, reflete a identidade cultural de uma sociedade e consiste em um objeto que pode desempenhar o papel de espelho social. Ao deter o olhar sobre os brinquedos, eles se ressignificam, despertando nos espectadores atuais diversos graus de apropriação e reinterpretação desses objetos. É fundamental que a sociedade tome consciência da importância desse patrimônio, levando em conta sua fragilidade - já que ele pode se perder - e seu pertencimento - já que é de toda a sociedade. Para fortalecer e afiançar a identidade cultural, é importante o resgate de brinquedos e jogos da cultura ou, mais especificamente, da sociedade à qual pertencemos. Ao conhecer e brincar com brinquedos e jogos de nossos pais e avós, reforçam-se complexas redes identitárias entre a criança, o adulto e sua comunidade.

Palavras-chave: Brinquedo, símbolo, identidade cultural, objetos lúdicos do século XX.
Abstract: The toy, full of symbolic connotation, reflects the cultural identity of a society and consists of an object that can play the role of social mirror. When we watch the toys, they get a new signification, arousing in the gazer several degrees of appropriation and reinterpretation of these objects. It is essential that society becomes aware of this heritage's importance and takes into account its fragility - heritage can be lost - and belonging - the heritage belongs to society as a whole. The rescue of the culture's toys and games and, more specifically, of the society to which we belong is important to strengthen and warrant the cultural identity. Knowing and playing with toys and games from our parents and grandparents reinforce complex identity networks among child, adult and their community.

Keywords: Toy, symbol, cultural identity, playful objects of the XXth century.

\section{O BRINQUEDO NO URUGUAI DE ONTEM: MENSAGEIRO DE UMA CULTURA}

Desde as últimas décadas do século XX, tem ocorrido uma política de globalização com inumeráveis progressos e transformações no campo da informação, das comunicações e dos avanços científicos. Nesse processo, as transformações são vertiginosas; ironicamente, ao que parece, a única coisa que permanece estável é a noção de transformação. As grandes nações vivem um 
comunicação \& educação • Ano XVII • número 1 • jan/jun 2012

desenvolvimento acelerado e a tecnociência expande suas fronteiras na medicina, na robótica - cada vez mais presente na indústria - e nas telecomunicações. Sua presença é cada vez maior no âmbito doméstico.

Diferentes foram também os espaços ocupados pelo brinquedo na história da humanidade. E, como tem acontecido com os mais diferentes símbolos da sociedade nesta era planetária, os brinquedos não deixam de ser um atraente objeto para as grandes empresas que os produzem e para a mídia que os difunde em massa - conquistando um público infantil que, a cada dia, tem acesso a eles em idade mais precoce devido à influência da televisão. Crianças de dois e três anos já pertencem à categoria de consumidores. Na tela, os mesmos brinquedos são exibidos em países da Europa, Oriente e América, e, vistos por crianças da mesma idade, são captados por sua sedução igualitária que arrasa e apaga nacionalidades e regionalismos.

Situando-me neste pequeno país - imerso, como não poderia deixar de ser, nesse processo de globalização -, atenho-me a dois eventos dos primeiros anos do século XXI - seus principais protagonistas são os brinquedos com os quais o Uruguai brincou em meados do século XX. O primeiro deu-se em agosto de 2004, quando foi publicado o livro Juguetes Uruguayos 1910-1960 [Brinquedos uruguaios 1910-1960], de autoria do pesquisador, professor e colecionador argentino Diego M. Lascano. Realizou-se também no Centro Cultural da Espanha, em Montevidéu, uma exposição de brinquedos chamada "Juguetes del fin del mundo" [Brinquedos do fim do mundo], entre agosto e setembro daquele ano.

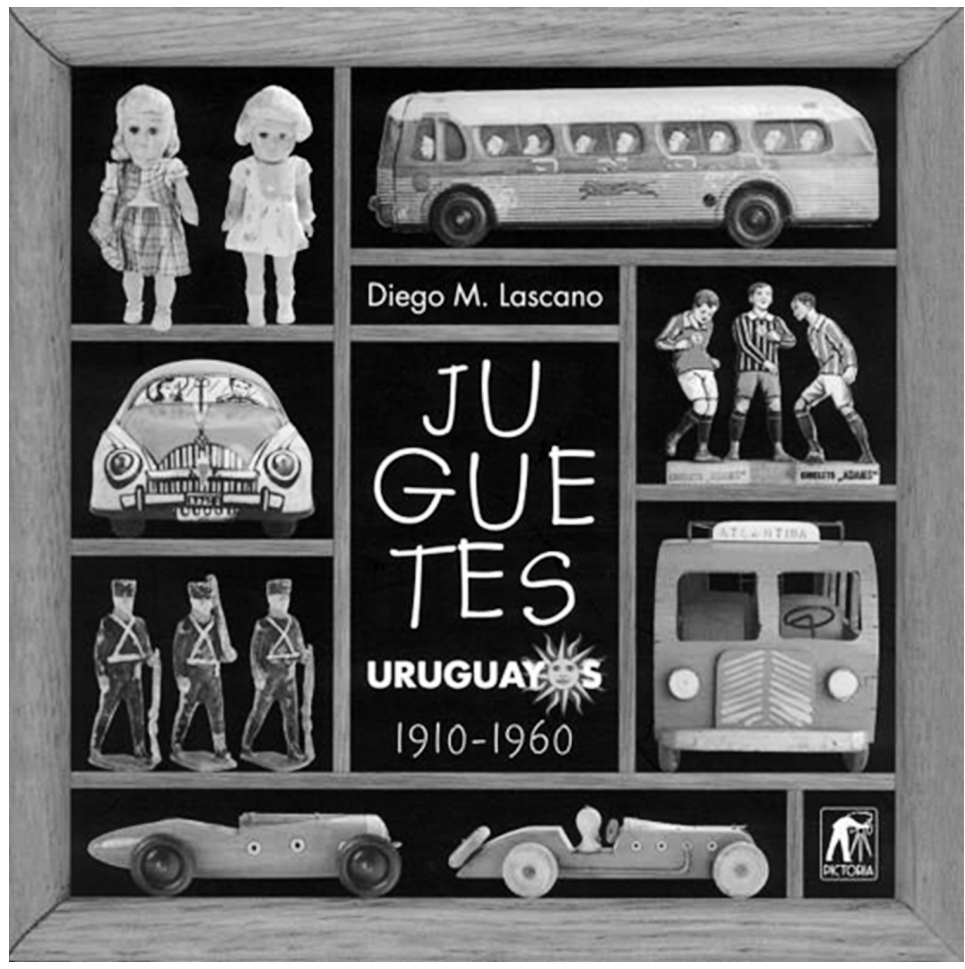

Capa da obra de Diego Lascano, Juguetes Uruguayos 1910-1960. 
Brinquedo, memória de uma sociedade - Josseline Ivette Cabanne

Nossas brincadeiras infantis fazem parte de nossa cultura? A pergunta pode desconcertar, já que leva a outro questionamento - o que é a cultura? -, cuja resposta é difícil. Ao menos não haverá o risco de equívoco se dissermos que é... tudo, sem exagerar, das mais altas expressões da arte e do intelecto até coisas tão cotidianas como o que vestimos, comemos e vivemos, incluindo a forma como brincamos em nossa infância. Por isso, não é descabido pensar que elementos tão cotidianos e ao mesmo tempo tão queridos como os brinquedos que nos divertiram em nossos primeiros anos - sejam eles carrinhos, bonecas ou trens - possam gerar interesse suficiente para se tornarem peças de museu, da mesma forma que um quadro famoso ou um objeto pertencente a um personagem histórico ${ }^{1}$.

O segundo evento a que fazemos referência foi a inauguração, entre julho e agosto de 2007, no Museo del Gaucho y la Moneda del BROU [Museu do Gaúcho e da Moeda do Banco da República Oriental do Uruguai], da exposição de jogos de mesa, intitulada "¿Querés jugar?" Los juegos de tablero desde el Valle de Ur (3000 a.C.) hasta nuestros días ["Quer brincar?” Os jogos de tabuleiro do Vale do Ur (3000 a.C) até nossos dias], organizada pelo colecionador uruguaio Winston Sterling. O organizador nos introduz à mostra dizendo que, em seu entender, o objetivo principal do evento consiste no fato de que "através do conhecimento dos diferentes jogos, estes continuem sendo um fator educativo e social pelo qual se aprende a conviver em harmonia e a compartilhar o tempo livre com a família e os amigos. Aprendamos a viver brincando! A vida é uma grande brincadeira!".

\section{POR QUE OS BRINQUEDOS?}

Com a fascinação que senti quando menina - quando tive brinquedos criados em sua chamada "época de ouro" - até nossos dias, quando, já adulta, os contemplo sem que diminua a fascinação que exercem sobre minha sensibilidade, é que empreendo esta viagem ao mundo dos brinquedos da década de 1950 .

Para realizá-la, consultei várias obras que abordam o jogo e o brinquedo. Visitei o colecionador Winston Sterling, entrevistei um fabricante de brinquedos e sua neta, assisti a programas de televisão infantis com suas inseparáveis propagandas, contemplei crianças de várias idades brincando, visitei lojas de brinquedos, brinquei, sonhei, recordei e me envolvi em sua atmosfera permeada de subjetividade e afeto. Como resultado disso, elaborei este trabalho.

Com sua simples presença, este artefato material é capaz de despertar em nossa memória imagens que nos remetem a uma época dourada do brinquedo no Uruguai; é o testemunho mudo e revelador de um passado, encerrando em si, ao mesmo tempo um universo de pequenas histórias que o vincula a seus usuários. Em muitos desses brinquedos, a passagem do tempo se faz sentir através de marcas, desgaste, oxidação ou corrosão na pintura. Seus donos, ontem crianças, hoje são avós - e esse elo lúdico com sua história nos permite fazer uma aproximação com os gostos e as preferências de uma sociedade que sofreu profundas transformações. Brinquedos e brincadeiras ostentam o sabor
1. CENTRO CULTURAL DA ESPANHA. Exposição "Juguetes del Fin del Mundo" [Brinquedos do fim do mundo]. Disponível em: <http://www.cce. org.uy/cce>. Acesso em: 09 out. 2004. 
comunicação \& educação • Ano XVII • número 1 • jan/jun 2012

do passado material e imaterial de uma sociedade complexa, produto da mistura cultural de variados contingentes de imigrantes.

Para analisar essa história e seus representantes, selecionei as informações coletadas em duas categorias bem distintas, com base nos já citados eventos: a exposição "Juguetes del fin del mundo" [Brinquedos do fim do mundo], do professor, historiador e colecionador argentino Diego Lascano, e seu livro Juguetes uruguayos 1910-1960 [Brinquedos uruguaios 1910-1960], cujos personagens principais são os brinquedos de madeira e de metal; e os jogos de mesa e tabuleiro do colecionador uruguaio Winston Sterling, com sua coleção: “¿Querés jugar?” [Quer brincar?], exposição enriquecida de abundante material histórico sobre a origem, as regras e o uso lúdico e social dos jogos de mesa.

No caso do pesquisador Lascano, sua iniciativa "Juguetes del fin del mundo" [Brinquedos do fim do mundo] visitou Montevidéu e Santiago do Chile, experiência à qual se soma a colaboração do escultor e colecionador chileno Juan Antonio Santis. Citando outra importante fonte de dados, Lascano atualiza com frequência seu trabalho exaustivo de pesquisa em um site chamado "Soldados de juguete fabricados en América del Sur y México" [Soldados de brinquedo fabricados na América do Sul e no México]².

\section{BRINQUEDOS NO URUGUAI - A "PÁTRIA GRINGA"}

Em poucos países do mundo, o processo imigratório teve um alcance tão crucial na configuração da sociedade local como no caso do Uruguai. Como mostra Juan Rial, durante os primeiros cem anos de sua vida independente, nossa sociedade teve nos estrangeiros um autêntico "fator definidor". De maneira particular, entre 1830 e 1890, o Uruguai mostrou-se "um espaço vazio aberto à duplicação" de estrangeiros, o que contribuiu para uma forte precocidade do fluxo migratório. A antecipação da corrente migratória junto a sua alta dimensão quantitativa (frente à população existente) reforçaram este perfil de "sociedade heterogênea"”.

O jogo, o brinquedo reforçam o sentido de identidade e pertencimento a uma sociedade. Os conteúdos da brincadeira e os materiais com os quais se produz um brinquedo têm estreita relação com o meio físico e social no qual estão imersos e imbricados, assim como com o momento histórico no qual são produzidos. Guardam estreitos laços de parentesco com a sociedade na qual são criados, possuindo uma carga ideológica e simbólica que reflete as trans-

2. LASCANO, Diego Juguetes Uruguayos 1910-1960 [Brinquedos uruguaios 1910-1960]. Santiago de Chile: Ediciones Pictoria Ltda., 2004.

3. CAETANO, Gerardo: RILLA, José. Historia Contemporánea del Uruguay. De la colonia al Mercosur [História contemporânea do Uruguai. Da Colônia ao Mercosul]. Montevidéu: CLAEH/Fin de Siglo, 2005 formações econômicas, sociais e tecnológicas de distintas épocas.

Tanto os brinquedos de Diego Lascano quanto os jogos de tabuleiro colecionados por Sterling provocam, em quem os contempla, curiosidade, surpresa e assombro - chegaram até nossos dias como objetos de um tempo passado. Neles se pode ler uma mensagem que, através dos canais sensoriais, toca a nossa sensibilidade. Nós os conhecemos através da apreensão visual, sonora e tátil; sua presença evoca, em muitos de nós, um entorno lúdico que permanece plenamente vigente. Sua mensagem, emitida em meados do século XX, opera como a "madalena" de Proust, recuperando a memória dos brinquedos e brincadeiras de uso cotidiano em outra época. 
Brinquedo, memória de uma sociedade - Josseline Ivette Cabanne

Os brinquedos expostos em Juguetes Uruguayos 1910-1960, tais como os jogos de tabuleiro colecionados por Sterling, recolhem ofícios e modelos disseminados na sociedade de seu tempo.

\section{A COLEÇÃO DE WINSTON STERLING DE JOGOS E BRINQUẺDOS}

Em nosso passado há muitos jogos que se tornaram atualmente misteriosos. Quanto a nosso futuro, depende de nossa capacidade de criar, não apenas técnicas, mas também sociedades e culturas novas. Depende, em resumo, de nossa capacidade de continuar jogando livremente ${ }^{4}$.

Subscrevendo o postulado da Organização das Nações Unidas para a Educação, a Ciência e a Cultura (Unesco), em um jogo ou batalha no qual o principal adversário é o esquecimento - e para continuar brincando livremente -, é que Winston Sterling coleciona jogos de mesa ou de tabuleiro. Começou pelos jogos de mesa de sua infância em Montevidéu e, por meio desses objetos, foi levado a rastrear suas próprias origens - chegando aos jogos de tabuleiro e jogos de Ur, cuja data de criação Sterling situa em três mil anos antes de Cristo.

O que é um jogo? De acordo com a definição, um jogo é o que você joga, e jogar é fazer um jogo. Este tem uma dupla estrutura baseada em objetivos e significados: Objetivos - o jogo é uma disputa em que se busca um objetivo final: ganhar.

Significados - Há um pacto entre regras e ferramentas através do qual é possível produzir uma situação de vitória.

Jogos de tabuleiro - Tabuleiro deriva de tabela, quadro. Um jogo de tabuleiro é aquele que pode ser jogado em uma superfície plana, como uma mesa, um tabuleiro ou no chão.

Os jogos se classificam em:

- Jogos de corrida: o objetivo é ser o primeiro a alcançar a meta. Exemplo: jogo da glória.

- Jogos de alinhamento ou configuração: sua lógica é ordenar as peças em uma linha ou em outra configuração. Exemplo: jogo da velha.

- Jogos de caça e perseguição: um jogador tem um grande número de peças e procura imobilizar as do oponente. Exemplo: "El zorro y las ocas" ["O lobo e os gansos"5].

- Jogos de guerra: neles é preciso capturar ou imobilizar as peças do inimigo. Exemplo: Xadrez.

- Jogos de mancala: o objetivo é capturar a maioria das peças do lado oponente. Exemplo: Aware.

- Jogos temáticos: caracterizados por simular ou representar atividades da vida real. Exemplo: Banco Imobiliário ${ }^{6}$.

Pode-se citar, também, objetos cujo uso ou significação tenham mudado com o tempo. Um exemplo bastante claro desse tipo de transformação são os jogos de mesa. Acredita-se que sua origem esteja nos rituais divinatórios ou ritos religiosos - de fato, muitos jogos de mesa mantêm até hoje uma forte
4. STERLING, Winston Investigación sobre el origen de los juegos de tablero y caja [Pesquisa sobre a origem dos jogos de tabuleiro e mesa]: depoimento (10.09.2008). Ainda não publicado. Entrevista concedida a Josseline Ivette Cabanne.

5. Jogo de tabuleiro semelhante ao brasileiro "Resta Um", porém jogado por dois oponentes. (N.T.)

6. STERLING, Winston. Catálogo de la Exposición "¿Querés Jugar?" Los Juegos de Tablero desde el Valle de Ur $(3.000$ a.C) hasta nuestros días" [Catálogo da Exposição "Quer jogar?" Os jogos de tabuleiro do Vale do Ur (3000 a.C) até nossos dias] (Colección Winston Sterling). Junio/ Julio 2007. Montevidéu: Espacio Cultural Banco República. Museos del Gaucho y de la Moneda, 2007. 
comunicação \& educação • Ano XVII • número 1 • jan/jun 2012

vinculação com o acaso e o que isso implica de predestinação na vida de uma pessoa -, mas também cumprem uma função recreativa.

Sterling, dotado de grande capacidade e meticulosidade, reconstruiu por sua conta alguns destes jogos. Ao visitar sua exposição de jogos de tabuleiro, foi uma experiência interessante deter o olhar sobre alguns deles. Observemos, primeiramente, o Ludo. Num nível simbólico, a criança, ao jogar o dado, sai de um lugar inicial e seu percurso posterior - no qual encontra obstáculos, desafios, avanços e retrocessos - está marcado pelo acaso. É uma atividade que, ao ser realizada, possibilita ao jogador interagir com seu futuro, adaptando-se e conhecendo as dificuldades e sucessos que, ao crescer, serão constantes em sua vida real.

Em um segundo momento, temos a loteria, que possui implicações subjetivas, já que seu jogo permite colocar o jogador "em uma trama de habilidade e sorte"

\section{BRINQUEDO, MEMÓRIA DE UMA SOCIEDADE}

Os brinquedos não são apenas objetos aperfeiçoados de acordo com avanços técnicos, critérios funcionais e comerciais, mas contribuem, com suas características formais, para nosso conhecimento de seu tempo, ajudando-nos a iluminar atitudes e estéticas imperantes. São a prova tangível do desenvolvimento técnico e formal, dando testemunho material de uma identidade que foi se configurando de modo paulatino, complexo e, muitas vezes, até contraditório. Constituem exemplos de seu meio ambiente, transcendendo a materialidade e nos permitindo elaborar ideias sobre a destreza de uma comunidade. $\mathrm{O}$ brinquedo contém componentes expressivos, simbólicos e culturais - razão pela qual muitos deles merecem entrar na categoria de bens patrimoniais.

\section{UMA VISÃO SENSÍVEL SOBRE O BRINQUEDO: "PEDREIRAS DE CRIAÇÃO"}

Vindas do passado, as vozes infantis se fazem presentes: elas chegam de outro Uruguai, de uma pequena população infantil composta, em sua maioria, de filhos de modestos imigrantes. Nesse lugar, chamado Canteras de Riachuelo ("Pedreiras de Riachuelo"), no Departamento de Colônia, a educação para sensibilidade ocupou um lugar de destaque.

A pesquisa a seguir trata de uma experiência realizada entre 1928 e 1935 na Escola Rural n. 56, de Canteras de Riachuelo. Foi desenvolvida pela diretora

7. TALLER BARRADAS. Canteras de creación. De la piedra a la forma: Riachuelo, una escuela transformadora [Pedreiras de criação. Da pedra à forma: Riachuelo, uma escola transformadora]. Montevidéu: Ediciones del Taba, 2005 da escola, María Cristina Zerpa, que ocupava aquele posto desde 1917, quando da inauguração da escola, e pelo professor Jesualdo Sosa, então seu marido.

Hoje, quando no campo da Educação Artística e Patrimonial recomenda-se enfatizar os três pilares educacionais "fazer, sentir e pensar" - mesmos pilares da Educação para a Arte -, convém resgatar o testemunho sensível de crianças uruguaias de ontem, assim como seu sentimento a respeito do brinquedo. Este testemunho foi recolhido por meio de um questionário que buscou verificar o 
Brinquedo, memória de uma sociedade - Josseline Ivette Cabanne

componente da sensibilidade unido ao desenvolvimento do pensamento crítico dos participantes.

\section{COMO VIRAM E SENTIRAM O BRINQUEDO, AS CRIANÇAS URUGUAIAS DE ONTEM}

\section{Questionário VII}

\section{O que é o brinquedo?}

- O brinquedo é parte da alegria na vida da criança. É uma coisa que, se é redonda, a criança às vezes lhe dá outra forma e vê nele até outros movimentos. E acaba achando que este ser calado é o silêncio...

- O brinquedo é um entretenimento que deixa as crianças felizes. Elas amam os brinquedos e os veem em sua alma interior, com clareza e doçura.

\section{Com que idade você gostou mais do brinquedo?}

- Quando o brinquedo era já para mim o protagonista sagrado da minha vida... E eu já conseguia contar e perguntar coisas para ele, coisas de seu mundo de sorrisos, pois todos os bonecos parecem tão alegres... (incompreensível) aos cinco anos.

- Quando pequena, aos dois ou três anos, porque eu achava que a vida era brincar, que não havia amarguras, que tudo era alegria e que, brincando, vivia e era feliz.

\section{Qual o seu brinquedo favorito e por quê?}

- Eu queria ter bonecas de todos os tamanhos para fazer uma escolinha onde elas contariam suas historinhas engraçadas para as crianças, ou puras para os pensadores artistas com suas profundas montanhas de pensamentos, e para os anõezinhos engraçados com barbas longas.

- Um trem que corresse bem rápido para girar como o mundo gira.

\section{Entre os brinquedos que se mexem e os que não se} mexem, quais são seus favoritos?

- Eu gosto mais dos que se mexem, porque me fazem rir bastante.

- Os que se mexem, e um trem de corda para passar dentro dos túneis e correr. Para fazer um mundo pequeno dentro da minha alma e ele ficar cada dia maior.

\section{Que brinquedo você gostaria de ser, se pudesse, e por quê?}

- Eu queria ser uma boneca para ficar numa vitrine com as outras.

- Um boneco, pra me abraçarem.

- Queria ser uma boneca humilde e simples e ficar num ranchinho onde as crianças fossem pobres para entender seus pensamentos, para deixar elas alegres quando ficassem tristes... 
comunicação \& educação • Ano XVII • número 1 • jan/jun 2012

\section{Você construiu um brinquedo alguma vez? Qual foi o resultado?}

- Fiz uma boneca de pano e, quando eu a levava para passear, acabou caindo no chão e a cabeça saiu.

- Um dia eu fiz uma boneca de pano. Minha irmãzinha dizia para fazer uma para ela, e como eu dizia que não, ela falava "essa boneca parece uma raposa". Não era uma obra-prima, mas também isso que ela dizia não era verdade. Ela tinha a cabeça deformada, mas isso era de tanto pensar: a coitada da boneca era muito inteligente com seus braços um mais curto que o outro, e com sua cara triste. Cara de passarinho triste na solidão do vento em que flutua...

\section{Se você fosse dar um brinquedo de presente, qual seria e por quê?}

- Se fosse para uma criança, eu daria um passarinho branco para servir de guia. E esse brinquedo não deixaria ela fazer nada de mau, porque, com seu olhar penetrante, faria ela entender o que é que tinha que fazer. Coisas como as que a criança sabe... e em seu voo plácido e de onduladas linhas, voar com o pensamento para as maiores colinas...

\section{IDENTIDADE, DIVERSIDADE CULTURAL, PATRIMÔNIO}

Os objetos patrimoniais, as produções artísticas, os bens simbólicos devem ser conhecidos, respeitados e queridos por todos os integrantes de uma sociedade, e não apenas pelos da classe dirigente. É oportuno recordar o que postula Bourdieu com respeito à apreciação e valorização de objetos e bens patrimoniais - e sobre como as atitudes em relação à arte estão fortemente marcadas pelo clima familiar. Bourdieu, como Darbel, ressalta a este respeito: "O amor à arte depende do capital cultural herdado, das disposições culturais transmitidas no seio familiar, muito mais do que das inclinações naturais e espontâneas" .

Diante de um mundo hiper-relacionado, no qual a comunicação é permanente, imediata, invasiva e até intimidadora, há que se estimular o contato real com os recursos do planeta. É fundamental o desenvolvimento dos três aspectos mencionados: corpo, inteligência, afetividade. Os empreendimentos de Lascano, com seu resgate dos brinquedos uruguaios, e do colecionador Winston Sterling são duas experiências que contribuem para o resgate de pequenos objetos patrimoniais, através dos quais se manifesta uma maneira particular de ser, sentir e jogar, próprias de uma sociedade uruguaia. Ambas as exposições de brinquedos e jogos de tabuleiro merecem ser conservadas e reconhecidas,

8. BOURDIEU, Pierre; DARBEL, Alain. L'Amour de l'art: les musées d'art européens et leur public [O amor pela arte: os museus de arte europeus e seu público]. Paris: Les Éditions de Minuit, 1969. já que evocam histórias de vivências relacionadas a referências e lugares que fizeram parte da paisagem cotidiana e sonora de uma trama composta de pequenos objetos, brinquedos, jogos.

O brinquedo, carregado de conotação simbólica, reflete a identidade cultural de uma sociedade e conforma um objeto que pode atuar como 
Brinquedo, memória de uma sociedade - Josseline Ivette Cabanne

espelho social. Jogos, brinquedos e sua história possibilitam conhecer o presente e o passado de uma sociedade. São o testemunho de uma época; sua presença nos permite compreender uma sociedade diferente da atual. São objetos que agregam a seu valor lúdico o valor estético, constituindo um bem etnológico - e, apesar do passado recente, interessam como objetos materiais e representativos de um patrimônio lúdico. Fica o convite a dedicarmos um novo olhar a eles.

\section{REFERÊNCIAS BIBLIOGRÁFICAS}

ARIÈS, Philippe; DUBY, Georges. Historia de la vida privada [História da vida privada]. Tomos 3 y 4. Madrid: Taurus Ediciones, 2001.

BALLART HERNÁDEZ, Joseph; JUAN I TRESSERRAS, Jordi. Gestión del patrimonio cultural [Gestão do patrimônio cultural]. Barcelona: Ed. Ariel, 2001.

BAUMAN, Zygmunt. Los retos de la educación en la modernidad líquida [Os desafios da educação na modernidade líquida]. Barcelona: Ed. Gedisa, 2007.

BOURDIEU, Pierre; DARBEL, Alain. L'Amour de l'art: les musées d'art européens et leur public [O amor pela arte: os museus de arte europeus e seu público]. París: Les Éditions de Minuit, 1969.

CAETANO, Gerardo; RILLA, José. Historia Contemporánea del Uruguay. De la colonia al Mercosur [História contemporânea do Uruguai. Da Colônia ao Mercosul]. Montevidéu: CLAEH/Fin de Siglo, 2005.

LASCANO, Diego M. Juguetes Uruguayos 1910-1960 [Brinquedos uruguaios 1910-1960]. Santiago do Chile: Ediciones Pictoria Ltda., 2004.

LONDON PARÍS. Catálogo. Edición de Oro [Catálogo. Edição de Ouro]. Montevidéu: London París, 1965.

MELGAR, Alicia; CANCELA, Walter. Economía: La hora del balance [Economia: a hora do balanço] en CLAEH (Edición especial para Ediciones de Montevidéu): El Uruguay de nuestro tiempo 1958-1983 [O Uruguai do nosso tempo 1958-1983]. Montevidéu: CLAEH, 1984.

STERLING, Winston. Catálogo de la Exposición “¿Querés Jugar?” Los Juegos de Tablero desde el Valle de Ur (3.000 a.C) hasta nuestros días" [Catálogo da Exposição "Quer jogar?” Os jogos de tabuleiro do Vale do Ur (3000 a.C) até nossos dias] (Colección Winston Sterling). Junio/Julio 2007. Montevidéu: Espacio Cultural Banco República. Museos del Gaucho y de la Moneda, 2007.

STERLING, Winston ( $\mathrm{s} / \mathrm{f}$ ). Investigación sobre el origen de los juegos de tablero y caja (sem publicação). [Pesquisa sobre a origem dos jogos de tabuleiro e mesa]. Mimeo. 
comunicação \& educação • Ano XVII • número 1 • jan/jun 2012

TALLER BARRADAS. Canteras de creación. De la piedra a la forma: Riachuelo una escuela transformadora. La obra de María Cristina Zerpa y Jesualdo Sosa [Minas da criação. Da pedra à forma: Riachuelo, uma escola transformadora. A obra de María Cristina Zerpa e Jesualdo Sosa]. Montevidéu: Ediciones del Taba, 2005 .

\section{Endereços eletrônicos}

CENTRO CULTURAL DA ESPANHA. Exposição "Juguetes del Fin del Mundo" [Brinquedos do fim do mundo]. Disponível em: <http://www.cce.org.uy/cce>. Acesso em: 09 out. 2004. 